\title{
Real-Time Position-Tracking Imaging
}

National Cancer Institute

\section{Source}

National Cancer Institute. Real-Time Position-Tracking Imaging. NCI Thesaurus. Code C116497.

An imaging technique that allows for the real-time tracking of an in vivo medical device, allowing for better control, positioning, and use of the device. 